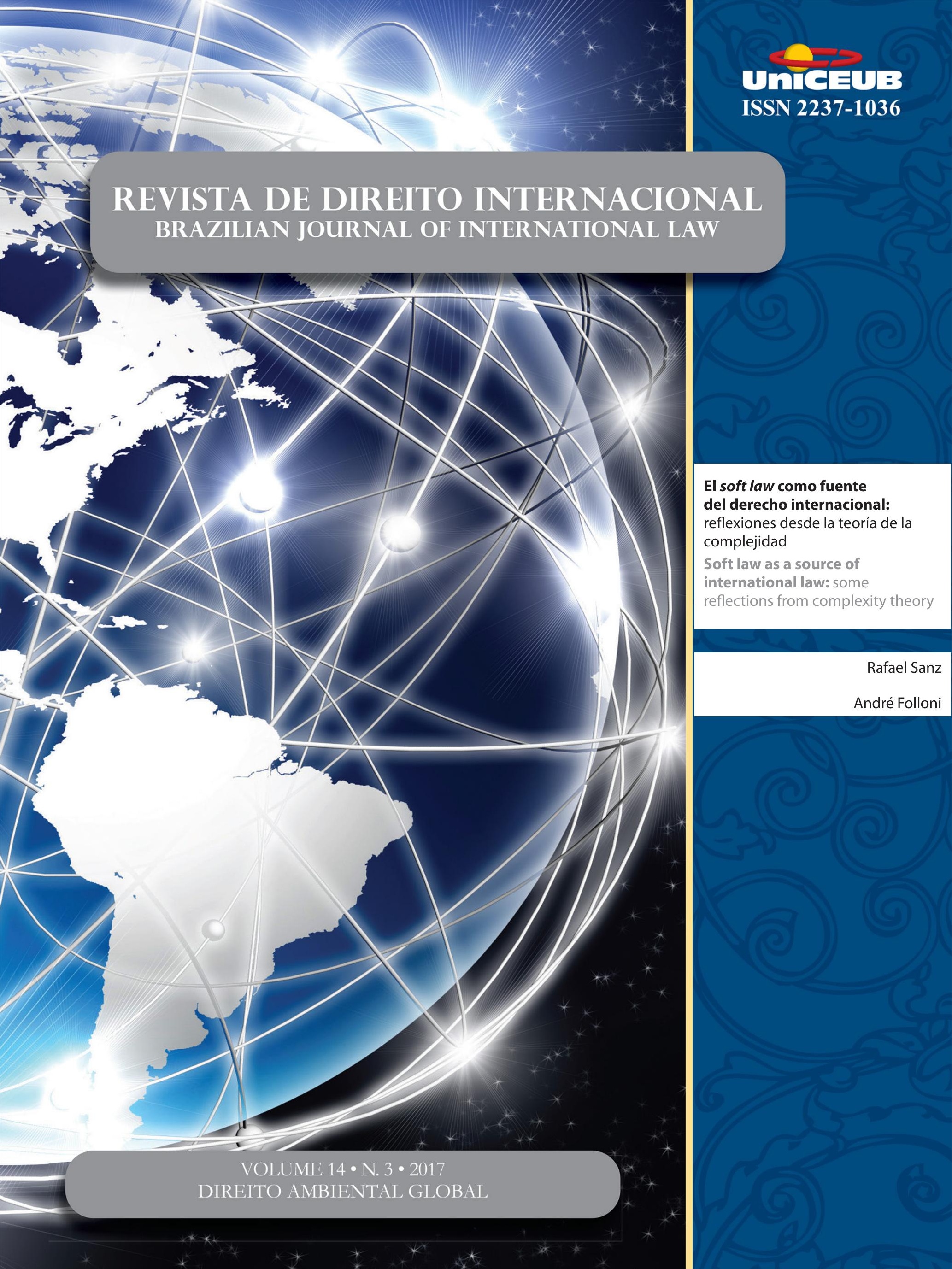




\section{Sumário}

I. Crônicas do Direito Internacional ...............................................1

CRÔNICAS DE DiREITO INTERNACIONAL PÚBLICO ........................................................................ 3

A política australiana de Refúgio e a decisão da Suprema Corte de PAPUA NOVA GUINÉ: A

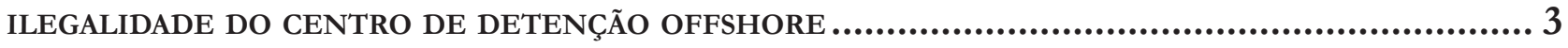

Tarin Cristino Frota Mont'Alverne e Ana Carolina Barbosa Pereira Matos

II. Dossiê especial: Direito Ambiental Global............................................ 7

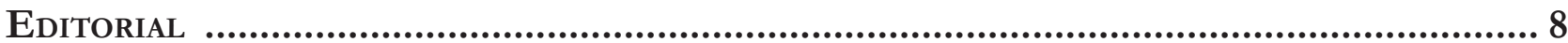

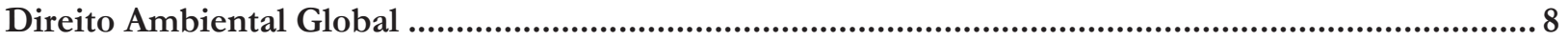

Priscila Pereira de Andrade

Direito Global: UMa TEORIA ADEQUAda PARA SE PENSAR o DiREITO AMBIENTAL? ................10 Arnaud Van Waeyenberge

“Complex is Beautiful": What role for the 2015 Paris Agreement in making the Effective Links within the Climate Regime Complex? .................................................21 Sandrine Maljean-Dubois e Matthieu Wemaëre

UNE ILLUSTRATION DU DROIT GLOBAL, LA LEX MERCATORIA CLIMATIQUE...............................31 Mathilde Hautereau-Boutonnet

OCÉANS ET CHANGEMENTS CLIMATIQUES : RECHERCHER LES INTERACTIONS AU SEIN DE LA FRAGMENTATION DU DROIT INTERNATIONAL

Sophie Gambardella

Une gouvernance globale du Climat par la transparence depuis l'Accord de Paris: Le DROIT GLOBAL DE L'ENVIRONNEMENT COMME SOLFÈGE? .56

Anne-Sofie Tabau 
LA PROGRESSIVE HARMONISATION DES RÈGLES DU PROCÈS ENVIRONNEMENTAL: MANIFESTATION

DE L'ÉMERGENCE D'UN DROIT GLOBAL? ............................................................69

Eve Truilhé-Marengo

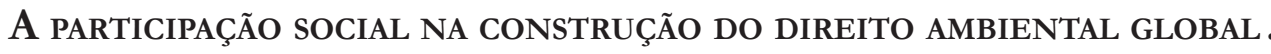
80 Michelle Lucas Cardoso Balbino

A PROTEÇÃo AMBIENTAL COMO EFEITO INDIRETO DO SISTEMA DE GESTÃo DE ENERGIA ISO 50001

Matheus Linck Bassani e Ricardo Serrano Osorio

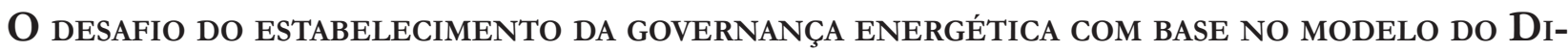
reito Administrativo Global: ESTUdo de CASO DAS ENERgias RENOVÁveis. 122 Alice Rocha da Silva

Othon Pantoja Oliveira de Azevedo

O PRINCÍPIO DA PARTICIPAÇÃo E A CRIAÇÃO E GESTÃo DAS ÁREAS PROTEGIDAS NA PERSPECTIVA DO DIREITO AMBIENTAL GLOBAI

Marcia Dieguez Leuzinger e Solange Teles da Silva

A teoria Ambientalista (GREen theOry) e a COMpetênCia CONSUltiva da CoRTE InTERAmericana de Direitos Humanos: O caso da Colômbia................................................. 148

Eduardo Biacchi Gomes e Ane Elise Brandalise

III. Artigos sobre outros temas....................................................... 160

30 anos do Protocolo de Montreal: Uma história de sucesso do Direito Ambiental

INTERNACIONAL 162

Fernando Rei e Valeria Cristina Farias

MinORIAS NACIONAIS, PROTEÇão INTERNACIONAL E TRANSNACIONALIDADE 182 Ana Maria D'Ávila Lopes e Luis Haroldo Pereira dos Santos Junior

Da relevância dos casos do Desarmamento Nuclear perante a Corte Internacional DE JUSTIÇA 203 Lucas Carlos Lima 
OS CONTROLES DE CONVENCIONALIDADE TRADICIONAL E INTERAMERICANO: INSTITUTOS DISTINTOS OU DUAS FACES DA MESMA MOEDA?

Gilberto Schäfer, Roger Raupp Rios, Paulo Gilberto Cogo Leivas e Jesus Tupã Silveira Gomes

EL SOFT LAW COMO FUENTE DEL DERECHO INTERNACIONAL: REFLEXIONES DESDE LA TEORÍA DE LA COMPLEJIDAD

Rafael Sanz e André Folloni

Ley de rotulación de alimentos de Chile: ¿'Traba comercial o protección de la saLUD?

Nicolás Cobo

IV. RESENHA DE LIVRO.

O CiVILIZAdor gentil das AmÉRICAS: CONSIDERAÇÕes EM TORNO DA OBRA THE HIDDEN HIStory of International LaW in the Americas: Empire and LeGal Networks, de Juan Pablo SCARFI 278

Cicero Krupp da Luz

'Mestizo International Law: A global intelectual history 1842 - 1933' De Autoría de Arnulf Becker-Lorca .283 Jimena Sierra-Camargo

América Latina em Continuidades e rupturas 287 Adriane Sanctis 


\title{
El soft law como fuente del derecho internacional: reflexiones desde la teoría de la complejidad* $^{*}$
}

\author{
Soft law as a source of international law: \\ some reflections from complexity theory
}

\author{
Rafael Sanz** \\ André Folloni***
}

\section{Resumen}

El sistema de fuentes en derecho internacional carece de una "meta-norma" o, en terminología hartiana, una regla de reconocimiento expresa. El surgimiento soft law o derecho blando se vincula tanto con la indeterminación estructural de las fuentes del derecho internacional como con la incapacidad de los modelos tradicionales para describir la realidad jurídica existente hoy día. Por esta razón, este paper intenta comprender el soft law como una fuente del derecho internacional a partir de su condición y de la comprensión del sistema jurídico como un sistema complejo adaptativo desde la teoría de la complejidad contemporánea. Utiliza como ejemplos el Código de conducta sobre la fiscalidad de las empresas de la Unión Europea y la lex mercatoria.

Palabras clave: Soft law. Fuentes del derecho. Derechos fundamentales. Complejidad.

\section{Abstract}

The system of sources in international law lacks a "meta-norm" or, in Hartian terminology, an explicit recognition rule. The emergence of soft law is linked to the structural indeterminacy of the sources of international law and to the inability of traditional models to describe the legal reality that exists today. For this reason, this paper tries to understand soft law as a source of international law based on its condition and the understanding of the legal system as a complex adaptive system based on the theory of contemporary complexity. It uses as examples the Code of Conduct on the taxation of European Union companies and the lex mercatoria.

* Recebido em 29/11/2017

Aprovado em 18/12/2017

** Investigador en Derecho tributario en la Universidad de Sevilla. E-mail : rsanz@us.es

*** Doctorado em Derecho (Universidad Federal de Paraná). Profesor Titular y Director del Posgrado en Derecho (Maestría y Doctorado) - Universidad Católica de Paraná. E-mail: folloni.andre@pucpr.br
Keywords: Soft law. Sources of Law. Fundamental Rights. Complexity 


\section{INTRODUCCIÓN}

El sistema de fuentes en derecho internacional carece de una "meta-norma" o, en terminología hartiana, una regla de reconocimiento expresa. Es decir: no existen criterios taxativos para determinar cómo se produce el derecho y, por tanto, cuándo una regla o principio forma parte del sistema jurídico internacional ${ }^{1}$. A falta de una meta-norma expresa, es tradicional la remisión al artículo 38.1 del Estatuto de la Corte Internacional de Justicia (en lo sucesivo, CIJ), que hace referencia a los tratados internacionales, la costumbre y los principios generales de derecho; además, el artículo se refiere -como medio auxiliar- a "las decisiones judiciales y las doctrinas de los publicistas de mayor competencia de las distintas naciones". Ahora bien: se ha señalado que este precepto (cuyo antecedente fue redactado en los años veinte del siglo pasado) no se adapta a la realidad actual y, por tanto, no puede considerarse "la última palabra" sobre el sistema de fuentes ${ }^{2}$. La doctrina considera también que se genera una distorsión al intentar aplicar con carácter general un precepto pensando para un órgano centralizado y construido sobre una concepción específica del derecho ${ }^{3}$.

El surgimiento del objeto de análisis de este trabajo, el soft law o derecho blando, se vincula tanto con la indeterminación estructural de las fuentes del derecho internacional ${ }^{4}$ como con la incapacidad de los modelos tradicionales para describir la realidad jurídica existente hoy día. Así, la propagación del término pone de manifiesto el desbordamiento del sistema tradicional de fuentes del derecho ${ }^{5}$. Ir más allá del territorio seguro del artículo 38 del Estatuto de la CIJ nos lleva a un ter-

1 PROST, Mario. The concept of unity in public international law. Oxford: Hart Publishing, 2012. p. 103.

2 HOOF, Godefridus van. Rethinking the sources of international law. Deventer: Kluwer, 1983. p. 82.

3 FALK, Richard A. On the quasi-legislative competence of the General Assembly. The American Journal of International Law, v. 60, n. 4, p. 782, Oct. 1966.

4 PROST, Mario. The concept of unity in public international law. Oxford: Hart Publishing, 2012, p. 103.

5 Se afirma que el soft law responde al desbordamiento de las fuentes del derecho internacional tal y como se reflejarían en el artículo 38 del Estatuto de la Corte Internacional de Justicia. SHELTON, Dinah. Commitment and compliance: the role of non-binding norms in the international legal system. Oxford: Oxford University Press, 2000. p. 1: la función del soft law se encuentra entre las cuestiones que plantea cuestiones sobre los límites del derecho internacional. reno "difícil" y "controvertido", pero es necesario explorarlo. THÜRER define el terreno denominado soft law como un "área gris entre el Derecho y la política"; DEL TORO HUERTA, como "el ámbito en el que se transforma la norma social en norma jurídica". Vemos así que, para buena parte de la doctrina, el soft law describiría el espacio que se extiende entre aquellas reglas evidentemente jurídicas y aquellas que, claramente, no lo son, sino que pertenecen a sistemas como el político o el moral.

El soft law, en su sentido más amplio, es -según DI ROBILANT- un conjunto de instrumentos regulatorios y mecanismos de gobernanza que, aunque implican algún tipo de compromiso normativo, no se fundamentan en reglas vinculantes o un régimen de sanciones formales ${ }^{9}$ El elemento común a la mayoría de las definiciones propuestas es que no tiene carácter vinculante pero sí "efectos prácticos" desde un punto de vista normativo, en el sentido de que es capaz de orientar la conducta de determinados agentes. Por último, una definición más precisa se deriva de la identificación de tres elementos de juridicidad (obligación, o carácter vinculante; precisión, o determinación de la conducta sin ambigüedades; y delegación, que implica que se reconoce la potestad de terceros para implementar, interpretar, aplicar y desarrollar las reglas, así como resolver los conflictos que se produzcan). Sobre estos tres elementos, y teniendo en cuenta que no operan como dicotomías sino que son cuestión de grado, el soft law se define como aquel conjunto de normas donde alguna de estas tres dimensiones han sido debilitadas.

Aunque puedan identificarse algunos elementos comunes a las diversas definiciones doctrinales, un problema es que el término propuesto carece en realidad de un significado unívoco, pese a su frecuente uso y a los encendidos debates sobre su utilidad o convenienci $a^{10}$. Es, más bien, un término "comodín" bajo el que se agru-

6 HILLGENBERG, Hartmut. A fresh look at soft law. European Journal of International Law, v. 10, n. 3, p. 499, 1999.

7 THÜRER, Daniel. The role of soft law in the actual process of european integration. In: Jacot-Guillarmod, O.; Pescatore, P. (Ed.), L'avenir du libre-échange en Europe: vers un espace économique européen? Zürich: Schultess Polygraphischer Verlag, 1990. p. 131.

8 DEL TORO HUERTA, Mauricio Iván. El fenómeno del soft law y las nuevas perspectivas del Derecho internacional. Anuario Mexicano de Derecho Internacional, v. 6, p. 530, 2006.

9 ROBILANT, Anna di. Genealogies of Soft Law. The American Journal of Comparative Law, v. 54, n. 3, p. 499-554, 2006.

10 ROBILANT, Anna di. Genealogies of Soft Law. The American Journal of Comparative Law, v. 54, n. 3, p. 499-554, 2006, p. 501. 
pa una gran variedad de instrumentos. DEL TORO ha llegado a afirmar, no sin ironía, que su función "no es, evidentemente, aclarar conceptos, pues tendría que empezar por aclararse a sí mismo" $"$.

Este trabajo pretende contribuir al debate sobre la naturaleza del soft law y su relación con el sistema de fuentes para aportar, en la medida de lo posible, un poco de esa necesaria claridad.

\section{UN ANÁLISIS DEL SOFT LAW A PARTIR DE TRES EXPERIENCIAS}

La pluralidad y heterogeneidad del fenómeno analizado justifican la particular elección metodológica que caracteriza este primer epígrafe. Comenzaremos por describir el surgimiento de algunos instrumentos que han sido calificados como "soft law" y, a partir del análisis de las experiencias concretas, intentaremos luego identificar elementos comunes mediante un proceso de inducción lógica. En parte, se trata de reconstruir el proceso de creación del propio término ya que, como no podría ser de otra forma, el concepto de soft law es posterior al fenómeno que describe.

El término "soft law" se emplea en un primer momento para hacer referencia a normas ineficaces ${ }^{12}$. Posteriormente, el concepto comienza a usarse en un sentido técnico específico similar al actual. A veces, la paternidad del concepto (en este sentido técnico) se atribuye a Richard BAXTER ${ }^{13}$, quien lo habría introducido en su curso de derecho internacional público en la Escuela de Derecho de Harvard ${ }^{14}$; o a Arnold D. McNAIR, aunque este lo habría empleado más bien como sinónimo de lex ferenda ${ }^{15}$. La cuestión es poco relevan-

11 DEL TORO HUERTA, Mauricio Iván. El fenómeno del soft law y las nuevas perspectivas del Derecho internacional. Anuario Mexicano de Derecho Internacional, v. 6, p. 543, 2006.

12 "Untaught law, conversely, is soft law, ineffective law, disappearing law, ultimately, dead law", según VALNDERBILT, Arthur T. The law school in a changing society: a law center. American Bar Association Journal, n. 32, p. 525, 1946.

13 Por ejemplo, en FRANCK, Thomas. The power of legitimacy among nations. Oxford: Oxford University Press, 1990. p. 29.

14 HASSAN, Parvez. The international covenants on human rights: an approach to interpretation. Buffalo Law Review, v. 19, n. 3, p. 35-50, 1970.

15 D'ASPREMONT, Jean. Softness in international law: a selfserving quest for new legal materials. The European Journal of International Law, v. 19, n. 5, 2008, p. 1081; FOOTER, Mary E. The (re)turn to 'soft law' in reconciling the antinomies in WTO law. Melbourne te: no nos interesa la autoría individual de un término, sino el proceso por el cual se le dota de un determinado significado intersubjetivo. Por lo demás, es pacífico que el término se originó en el derecho internacional público, probablemente por sus particulares características, y luego se ha trasladado otros contextos, incluidas numerosas ramas del derecho interno ${ }^{16}$.

Los tres fenómenos que se analizarán son las resoluciones de la Asamblea General de la Organización de las Naciones Unidas; el Código de conducta sobre la fiscalidad de las empresas, como ejemplo de instrumento no vinculante formulado en el seno de la Unión Europea; y la llamada lex mercatoria. Nuestra intención no es, ni mucho menos, aportar nada novedoso a cada debate concreto; sino analizar cómo surge cada nuevo instrumento y cómo le siguen diversos intentos de categorización por parte de la doctrina y, en su caso, de encuadre en el sistema de fuentes. El objetivo es, en suma, esbozar una especie de genealogía del soft law. Nuestro foco estará no en cada instrumento en sí, sino en el debate jurídico que se genera y las circunstancias en las que se emplea este término.

\subsection{Las resoluciones de la Asamblea General de las Naciones Unidas}

Algunos de los primeros usos del concepto de "soft law" se refieren a las resoluciones de las instituciones de la Organización de las Naciones Unidas, sobre todo de la Asamblea General, y a su integración o no (y, en su caso, en qué circunstancias) en el sistema de fuentes del derecho internacional público.

La cuestión práctica que la doctrina trató de determinar era si las resoluciones de la Asamblea General tenían la capacidad de influir en la conducta de los Estados con carácter general, pese a que la Carta de las Naciones Unidas no le atribuya capacidad normativa alguna. El derecho internacional, originariamente, se estructura en torno a los acuerdos entre Estados soberanos. Uno de los objetivos principales de estos agentes es evitar verse vinculados sin que medie su expreso consentimiento. Para consentir de manera efectiva, los Estados deben saber qué tipo de actuación creará una

Journal of International Law, v. 11, p. 2, 2010.

16 ROBILANT, Anna di. Genealogies of Soft Law. The American Journal of Comparative Law, v. 54, n. 3, p. 499-554, p. 499, 2006. 
expectativa de cumplimiento futuro ${ }^{17}$. Este era el marco conceptual bajo el cual se analizó la función de las resoluciones de la Asamblea General de las Naciones Unidas. ¿No es incompatible con este principio estructural del derecho internacional la idea de que el soft law pueda implicar cierta vinculación? En principio parece serlo, y de hecho la idea de que las resoluciones podrían constituirse como una fuente del derecho internacional parte, en primera instancia, del mundo académico ${ }^{18}$ más que de unos Estados celosos de su soberanía.

Siguiendo a KERWIN, pueden identificarse tres categorías de argumentos a favor del carácter vinculante de las resoluciones de la Asamblea General. Un grupo afirma que la autoridad de la Asamblea se deriva de la Carta de las Naciones Unidas, que es un tratado que vincula a todos los Estados miembros. De modo muy interesante, se sugirió en esta línea que no existe un órgano superior que pueda determinar cuál es la competencia de la Asamblea y que, por tanto, "los poderes de la Asamblea General pueden evolucionar de manera orgánica para enfrentarse a nuevas circunstancias"19. Un segundo grupo afirma que las resoluciones de la Asamblea pueden remplazar u operar como algunos de los elementos que determinan la existencia de una costumbre internacional ${ }^{20}$. Por último, un tercer grupo (bastante heterogéneo) conecta el carácter vinculante de las resoluciones con la naturaleza representativa de la Asamblea; entre ellos, podemos señalar a quienes han considerado que la Asamblea tiene una función cuasi-legislativa ${ }^{21}$.

17 KERWIN, Gregory J. The role of United Nations General Assembly resolutions in determining the principles of international law in United States courts. Duke Law Journal, n. 4, p. 877, 1983.

18 KERWIN, Gregory J. The role of United Nations General Assembly resolutions in determining the principles of international law in United States courts. Duke Law Journal, n. 4, p. 890, 1983.

19 CASTAÑEDA, Jorge. Legal Effects of United Nation Resolutions. New York: Columbia University Press, 1969. p. 16. Por el contrario, HILLGENBERG afirma que las competencias de la Asamblea General sólo pueden modificarse mediante la enmienda de la Carta de las Naciones Unidas. HILLGENBERG, Hartmut. A fresh look at soft law. European Journal of International Law, v. 10, n. 3, p. 515, 1999. 20 Véase DUPUY, que al mismo tiempo afirma que "en un mundo donde el número de Estados se ha cuadriplicado y se han constituido grupos diferenciados en los planos económico, social, ideológico, una parte del derecho consuetudinario está condenado a la explosión" DUPUY, Rene-Jean. Droit déclaratoire et droit programmatoire: de la coutume sauvage à la 'soft law'. In: Société Française pour le Droit International (Ed.). L'Élaboration du droit international. Paris: Pedone, 1975. p. 134.

21 FALK, Richard A. On the quasi-legislative competence of the General Assembly. The American Journal of International Law, v. 60, n.
Por el contrario, entre los argumentos contrarios a la inclusión de las resoluciones de la Asamblea General en el sistema de fuentes se encuentran los relativos a la existencia de contradicciones entre ellas o el hecho de que su redacción sea excesivamente vaga; se ha señalado también que no son indicadores fiables de la opinión mundial, por diversos motivos ${ }^{22}$. En este sentido, es interesante la propuesta realizada en su momento por BLEICHER, quien consideró que sólo podría considerarse que tienen cierto efecto normativo (en el sentido de creación de expectativas de cumplimiento futuro) aquellas resoluciones frecuentemente citadas por la propia Asamblea General, que expresarían convicciones estables en el tiempo ${ }^{23}$.

En el seno de este debate podemos detectar el empleo del término "soft law" en el sentido técnico que luego se ha hecho dominante ${ }^{24}$. Por ejemplo, en 1965, GROSS enmarcó el debate sobre la naturaleza jurídica y los efectos de las resoluciones de la Asamblea General en la diferencia entre el "hard law" (tratados y convenciones) y el "soft law" (resoluciones y declaraciones) ${ }^{25}$.

Puede parecer una obviedad afirmar que el debate sobre la naturaleza de las resoluciones de la Asamblea General de la ONU es consecuencia de la creación de dicha organización. Sin embargo, nos da una primera idea relevante: la aparición de nuevos actores en el ámbito internacional implica una tensión sobre el sistema de fuentes.

4, p. 782-791, Oct. 1966.

22 KERWIN, Gregory J. The role of United Nations General Assembly resolutions in determining the principles of international law in United States courts. Duke Law Journal, n. 4, p. 893-894, 1983. 23 BLEICHER, Samuel A. The legal significance of re-citation of General Assembly Resolutions. The American Journal of International Law, v. 63, n. 3, p. 446, Jul. 1969.

24 También, en algunos trabajos publicados en los años sesenta encontramos aún el uso de la expresión "soft law" como un equivalente aproximado de "norma ineficaz", en el sentido que señalamos supra. Por ejemplo, cuando SCHACHTER describe en un trabajo de 1964 la Carta de las Naciones Unidas como "soft law", se está refiriendo a que contiene principios de carácter general y abstracto, que deben concretarse a través de su aplicación a casos específicos por parte de las instituciones de las Naciones Unidas. En este sentido, "hard law" se refiere a derecho eficaz, o derecho preciso. SCHACHTER, Oscar. The quasi-judicial role of the Security Council and the General Assembly. The American Journal of International Law, v. 58, n. 4, p. 960-965, Oct. 1964; véase también HIGGINS, Rosalyn. The development of international law by the political organs of the United Nations. Proceedings of the American Society of International Law at Its Annual Meeting, v. 59, p. 116-124, Apr. 1965.

25 GROSS, Leo. The United Nations and the role of law. International Organization, v. 19, n. 3, p. 555, 1965. Véase también CHRISTOL, Carl Q. Communist China and international law: strategy and tactics. The Western Political Quarterly, v. 21, n. 3, Sep. p. 464, 1968. 
La doctrina tradicional sobre las fuentes del derecho fue formulada antes de la creación de organizaciones internacionales y, evidentemente, no podía tener en cuenta el efecto de la creación progresiva de una comunidad internacional ${ }^{26}$, proceso que se pone de manifiesto a través de elementos como la fundación de la Organización de las Naciones Unidas, la profunda reformulación de los derechos humanos ${ }^{27}$, la protección del medio ambiente, la explotación de los océanos, la exploración espacial, o la descolonización y la solidaridad como fundamento del desarrollo económico de los pueblos.

Curiosamente, durante la redacción del Estatuto de la CIJ se rechazó una propuesta para que la Asamblea General tuviera potestad legislativa, lo cual hubiera implicado una reformulación expresa del sistema de fuentes $^{28}$. Se impuso un carácter más continuista, que se limitó a recoger ideas ya consolidadas.

Sin embrago, tal y como afirmó SCHACHTER, los órganos políticos de las Naciones Unidas son centros de autoridad en un sistema institucional complejo a través de los cuales se desarrollan actividades que tienen un impacto en las políticas estatales ${ }^{29}$. Posteriormente, la descolonización implicó un cambio profundo en la composición de la comunidad internacional (que dejó de ser fundamentalmente eurocéntrica y pasó a tener una mayor heterogeneidad), lo cual introdujo mutaciones en su agenda ${ }^{30}$. En este sentido, DUPUY vincula la emergencia de los Estados del entonces llamado "tercer mundo" con la afirmación de nuevos principios que no se expresan a través de las fuentes tradicionales, sino entre otros instrumentos- mediante "declaraciones co-

26 DUPUY, Rene-Jean. Droit déclaratoire et droit programmatoire: de la coutume sauvage à la 'soft law'. In: Société Française pour le Droit International (Ed.). L'Élaboration du droit international. Paris: Pedone, 1975. p. 133.

27 "No se puede entender ni el hecho, ni la estructura, ni la dinámica de la expansión de los derechos humanos después de 1945 si no se interpreta como una respuesta a la experiencia de una catástrofe política y moral [...] la Declaración Universal de los Derechos Humanos no es la simple continuación de la historia de los derechos humanos desde el siglo XVII o XVIII" MENKE, Christoph; POLLMANN, Arnd. Filosofía de los derechos humanos. Barcelona: Herder, 2010. p. 21.

28 KERWIN, Gregory J. The role of United Nations General Assembly resolutions in determining the principles of international law in United States courts. Duke Law Journal, n. 4, p. 879, 1983.

29 SCHACHTER, Oscar. The quasi-judicial role of the Security Council and the General Assembly. The American Journal of International Law, v. 58, n. 4, p. 960-965, Oct. 1964.

30 PETERSON, M. J. The UN General Assembly. Abingdon: Routledge, 2006. p. 134. munes cuyo valor y efectos jurídicos son aún inciertos", y que reciben el nombre de soft law ${ }^{31}$.

Por tanto, y en lo que por ahora nos interesa, la aparición de la Asamblea General en el sistema de instituciones del derecho internacional y, posteriormente, la independencia de nuevos Estados del "tercer mundo" con unos intereses diferentes a los de los países desarrollados, crearon nuevos medios de interacción, nuevos actos comunicativos y nuevos discursos. Ante la evidente imposibilidad de ignorarlos, la doctrina intentó incluirlos en el modelo del derecho internacional de varias formas: encajándolos en elementos que ya existían (es el caso de las teorías que vinculan las resoluciones de la Asamblea General con la costumbre); proponiendo una reescritura formal del sistema de fuentes (con una propuesta en tal sentido durante la redacción del Estatuto de la CIJ) o aplicando una categoría, la del soft law, de contornos poco nítidos y cuya interacción con otros elementos no es en absoluto clara.

\subsection{El Código de conducta sobre la fiscalidad de las empresas}

La Unión Europea se puede describir como una entidad supranacional de integración de Estados para la persecución de una serie de objetivos fundamentalmente económicos, pero también de otra naturaleza. Esta entidad está en permanente construcción desde 1950 a través de una serie de procesos de ampliación de competencias, creación de nuevas instituciones y expansión de su ámbito territorial. Por ese motivo, el sistema jurídico de la Unión Europea es particularmente dinámico. A lo largo de su historia ha debido aplicar muy diversas estrategias para solventar los problemas a que ha debido enfrentarse; el Código de conducta sobre la fiscalidad de las empresas es uno de ellos.

El sistema de la Unión Europea se caracteriza porque sus instituciones han admitido y promovido desde el inicio el uso conjunto de mecanismos de hard y de soft law ${ }^{32}$. El propio artículo 288 del Tratado de Funciona-

31 DUPUY, Rene-Jean. Droit déclaratoire et droit programmatoire: de la coutume sauvage à la 'soft law'. In: Société Française pour le Droit International (Ed.). L'Élaboration du droit international. Paris: Pedone, 1975. p. 134.

32 CRAIG, Paul; DE BÚRCA, Gráinne. EU Law: text, cases, and materials. 6. ed. Oxford: Oxford University Press, 2015. p. 107; TRUBEK, David M.; COTTRELL, Patrick; NANCE, Mark. 'Soft law', 'hard law' and EU integration: toward a theory of hybridity. University of Wisconsin Legal Studies Research Paper, n. 1002, p. 65, nov. 
miento de la Unión Europea (en lo sucesivo, TFUE), en su versión consolidada tras el Tratado de Lisboa, que recoge el elenco actual de "actos jurídicos de la Unión"33, incluye entre las fuentes (secundarias) principales del derecho de la UE dos elementos, los dictámenes y las recomendaciones, de los que se dice expresamente que tienen carácter no vinculante (y que la doctrina, consecuentemente, ha calificado como "soft law"34). Además, existe toda una serie de fuentes atípicas, no previstas expresamente en los Tratados, que también pueden considerarse soft law. Normalmente se trata de instrumentos dictados unilateralmente por la Comisión y el Consejo, aunque hay otros supuestos ${ }^{35}$. Existen encendidos debates en la doctrina sobre su naturaleza y también sobre su utilidad o conveniencia, aunque nuestro interés es, de nuevo, analizar estos debates desde un punto de vista externo más que entrar en ellos. Los debates doctrinales y las iniciativas adoptadas por las instituciones sobre cómo categorizar estudios dispositivos cuasi normativos nos interesan como objeto de estudio.

Tradicionalmente, los Estados europeos se han mostrado reacios a ceder su soberanía en el ámbito de la fiscalidad directa por su importancia recaudatoria y como instrumento de política fiscal ${ }^{36}$. Pero el hecho de que la creciente integración económica en el marco del mercado único europeo no haya ido acompañada de una homogeneización de los sistemas tributarios ha provocado toda una serie de problemas: entre ellos, diversos obstáculos jurídicos a las actividades u operaciones económicas transfronterizas o un grado elevado de competencia fiscal entre Estados miembros. Las instituciones han reaccionado para cubrir la falta de iniciativa de los Estados (y el bloqueo en el seno del Consejo, competente para adoptar medidas de armonización tributaria pero que requiere unanimidad para ello) promoviendo un ejercicio amplio de sus competencias o promoviendo

2005.

33 En la versión original del Tratado de Roma de 1957, que creó la Comunidad Económica Europea, el artículo equivalente es el 189, que recoge el mismo listado de fuentes.

34 ALONSO GARCÍA, Ricardo. El soft law comunitario. Revista de Administración Pública, n. 154, p. 64, 2001.

35 SENDEN, Linda. Soft law in European Community law. Oxford: Hart Publishing, 2004. p. 113.

36 ADAMCZYK, Łukasz; MAJDAŃSKA, Alicja, The sources of EC law relevant for direct taxation. In: LANG, Michael et al. Introduction to european tax law: direct taxation. Vienna: Spiramus Press, 2008. p. 20; y ROCCATAGLIATA, Franco. Diritto tributario comunitario. In: UCKMAR, Victor (Ed.). Diritto tributario internazionale. Padova: CEDAM, 2005. p. 1230-1231. la coordinación a través de medidas de soft law, como alternativa a la armonización vinculante.

Concretamente, el Código de conducta sobre la fiscalidad de las empresas fue adoptado para dar respuesta a la competencia fiscal lesiva. Con este término, la Unión Europea se refiere a aquellas manifestaciones de competencia entre sistemas tributarios que producen efectos que deben evitarse, como una pérdida de ingresos fiscales (a través del fenómeno conocido como "race to the bottom") o de eficiencia en la asignación de recursos (en la medida en que las decisiones empresariales se tomen puramente por motivos tributarios).

El Código de conducta describe qué es una medida fiscal "potencialmente perniciosa" (epígrafes A y B) y contiene un compromiso de los Estados miembros de no introducir nuevas medidas de este tipo (epígrafe C) y de desmantelar progresivamente las ya existentes (epígrafe D). Aunque el Código es "un compromiso político" y, por tanto, no influye en los derechos y obligaciones de los Estados miembros ni en las competencias de estos y de la Unión Europea ${ }^{37}$, también se prevé un compromiso de comunicación de medidas vigentes o en tramitación que pudieran entrar en el ámbito de aplicación del Código (epígrafe E) y un procedimiento de evaluación de las medidas perniciosas (epígrafes $\mathrm{F}$ a I), así como un procedimiento de seguimiento y revisión de los resultados del propio Código (epígrafe N) y otra serie de disposiciones heterogéneas. Uno de los principales resultados de los procedimientos de evaluación es el llamado Informe Primarolo, aprobado el 29 de noviembre de 1999, que recoge una lista de 66 medidas que han merecido la consideración de perjudiciales tras la evaluación.

Además de ser un dispositivo no vinculante, desde un punto de vista formal se trata de un acto atípico, concretamente de una resolución. Tal y como ha señalado el Abogado General LA PÉRGOLA, en sus conclusiones presentadas en el caso NIFPO ${ }^{38}$, las resoluciones son uno de esos actos atípicos
(no menos importantes) a los que el Consejo y la
Comisión recurren en ocasiones -desde la óptica,
sin embargo de la creciente integración entre los
ordenamientos jurídicos de los Estados miembros-
para expresar su voluntad política, precisando los

37 Así se señala expresamente en el preámbulo del Código. 38 Las conclusiones de los Abogados Generales del Tribunal de Justicia de la Unión Europea son una especie de dictamen no vinculante previo a la sentencia del Tribunal. 
elementos de los acuerdos alcanzados en el seno de la Institución con el fin de evitar que dichos acuerdos puedan ser cuestionados ${ }^{39}$.

Encontramos dos elementos interesantes en las palabras del Abogado General. En primer lugar, la función que LA PÉRGOLA atribuye a las resoluciones es una tradicionalmente vinculada a los sistemas jurídicos: la estabilización de expectativas (concretamente, se expresan determinados acuerdos de voluntad para que no sean cuestionados en el futuro). En segundo lugar, la referencia a una "expresión de voluntad política". El soft law se ha considerado una cuestión fronteriza entre el derecho y la política; con todo, es evidente que una ley o un tratado internacional (ambos instrumentos jurídicamente vinculantes, pertenecientes al hard law) son también expresiones de voluntad política, que pasan a tener efectos jurídicos porque interaccionan para ello con otros elementos del sistema.

Esta interacción, en el caso del Código, ya se puede prever con la redacción del propio texto. El epígrafe J hace referencia al régimen de ayudas de Estado (actuales artículos 107 a 109 TFUE), que prohíbe aquellas medidas estatales (incluidas las de naturaleza tributaria) otorgadas por un Estado miembro o con recursos públicos, que concedan una ventaja a sus beneficiarios, beneficiando a determinadas empresas o producciones y afectando (incluso solo potencialmente) a la competencia o a los intercambios entre Estados. Existe un deber de los Estados de comunicar medidas que potencialmente sean ayudas de Estado (en este caso, se trata de una obligación jurídicamente vinculante), que quedan sujetas a revisión por parte de la Comisión Europea. La doctrina señala cómo el Código de Conducta fue reforzado por la aplicación más estricta, por parte de la Comisión, de las reglas sobre ayudas de Estado ${ }^{40}$.

GRIBNAU señala el "hecho notable" de que el informe Primarolo ha sido presentado a los Estados que han ingresado en la Unión Europea desde entonces como parte del acervo comunitario: es decir, como aquellas reglas que deben aceptarse para poder formar parte de la Unión. Como consecuencia, a su vez, los nuevos Estados han ejercido una fuerte presión sobre los que ya formaban parte de la Unión en 1999 para

39 Conclusiones del Abogado General LA PÉRGOLA presentadas el 30 de septiembre de 1997, NIFPO, C-4/96, Rec. p. I-681, ap. 56.

40 GRIBNAU, Hans. Soft law and taxation: EU and international aspects. Legisprudence, v. 2, n. 2, p. 84, 2008; que se garantice la plena aplicación del Código; también señala que existe una retroalimentación entre el Código de conducta y otros mecanismos de soft law que pertenecen a ámbitos diferentes (como los derivados del informe de la OCDE Harmful Tax Competition: An Emerging Issue, de 1998) ${ }^{41}$.

Los Estados miembros han reformado la mayor parte de sus medidas tributarias para adaptarse a las reglas del Código de conducta ${ }^{42}$. Su eficacia no sólo proviene de la interacción entre mecanismos de soft law y de hard law, sino que en las reflexiones de la doctrina están presentes algunos de los mecanismos mediante los cuales el soft law produce un impacto sobre la conducta: la voluntad de los Estados de evitar críticas ("shaming"), que es una de las causas de la eficacia de instrumentos como listas negras; la difusión de conductas por imitación o a través del discurso (es el caso de la interacción entre nuevos y antiguos Estados de la Unión en torno al informe Primarolo); o la creación de redes ("networking"), por ejemplo a través del grupo de trabajo que analiza las medidas potencialmente perniciosas. Estas redes facilitan la deliberación (el Código ha sido calificado como un instrumento de coordinación de las políticas tributarias, ya que prevé que durante la elaboración de nuevas medidas tributarias un Estado debe consultar con el resto cuando dicha medida puede ser potencialmente lesiva ${ }^{43}$ ) y el aprendizaje ${ }^{44}$.

\subsection{Lex mercatoria}

Desde los años 1980, las empresas transnacionales han impulsado con éxito un nuevo sistema jurídico, en gran medida no estatal, que regula las operaciones mercantiles transfronterizas y que recibe el nombre de lex mercatoria. Las empresas pretenden minimizar su relación con el marco de regulación estatal ${ }^{45}$ porque cada

41 GRIBNAU, Hans. Soft law and taxation: EU and international aspects. Legisprudence, v. 2, n. 2, p. 84, 2008.

42 GRIBNAU, Hans. Soft law and taxation: EU and international aspects. Legisprudence, v. 2, n. 2, p. 83-84, 2008.

43 GRIBNAU, Hans. Soft law and taxation: EU and international aspects. Legisprudence, v. 2, n. 2, p. 82, 2008.

44 Véase TRUBEK, David M.; COTTRELL, Patrick; NANCE, Mark. 'Soft law', 'hard law' and EU integration: toward a theory of hybridity. University of Wisconsin Legal Studies Research Paper, n. 1002, p. 79 , nov. 2005.

45 SWEET ha afirmado que la lex mercatoria "parasita" al Estado: al tiempo que lo emplea para garantizar la efectividad de sus normas, las empresas transnacionales intentan minimizar el control estatal sobre su actividad económica. SWEET, Alec Stone. The new lex 
vez les es menos útil; y quieren además evitar cualquier tipo de control externo que no esté sujeto a su aprobación. Se ha afirmado que una de sus características más destacadas es que el contrato desplaza a la ley como fuente central del derecho ${ }^{46}$. Su aplicación se confía a un sistema de tribunales de arbitraje de carácter privado, pero cuyos laudos tienden a ejecutarse a través del derecho estatal.

Evidentemente, la propia naturaleza del sistema y su encaje en los modelos predominantes de qué es derecho se encuentra bajo discusión teórica. Como señalan KERCHOVE y OST, la lex mercatoria puede considerarse tanto no jurídica (un conjunto de usos comerciales que emanan del "cuerpo social") como jurídico ("expresión de principios generales del derecho internacional" ${ }^{47}$. De nuevo nos encontramos, por tanto, en "el ámbito en el que se transforma la norma social en norma jurídica", recordando la cita de DEL TORO HUERTA.

Gran parte de la doctrina que ha negado tradicionalmente el carácter jurídico de la lex mercatoria criticaba su legitimidad, en parte porque rechazaba la posibilidad de que el derecho pueda ser creado por actores privados. Sin embargo, las críticas actuales se centran más bien en las dudas sobre la definición de su contenido, su cognoscibilidad y predictibilidad ${ }^{48}$.

Otra conclusión que extraemos al estudiar el análisis que la doctrina académica hace de la lex mercatoria es la siguiente: para muchos autores resulta clave en la práctica, a la hora de determinar su carácter jurídico, el reconocimiento por parte de determinados operadores jurídicos, fundamentalmente los jueces. Así, CUNIBERTI $^{49}$, MUSTILL ${ }^{50}$ o TEUBNER se encuentran entre los autores que dan un lugar importante en sus análisis al hecho de que los jueces acepten o no la lex

mercatoria and transnational governance. Journal of European Public Policy, n. 13, p. 627-646, 2006.

46 GALGANO, Francesco. The new lex mercatoria. Annual Survey of International \& Comparative Law, v. 2, n. 1, p. 103, 1995.

47 KERCHOVE, Michel van de; OST, François. Le droit et les paradoxes du jeu. Paris: PUF, 1992. p. 181.

48 JEMIELNIAK, Joanna. Application of transnational substantive rules to commercial disputes: on creative aspects of arbitral decision making. ZIRK-SADOWSKI, Marek; GOLECKI, Mariusz Jerzy; WOJCIECHOWSKI, Bartosz (Ed.). Multicentrism as an emerging paradigm in legal theory. Frankfurt am Main: Peter Lang, 2009. p. 260.

49 CUNIBERTI, Gilles. Three theories of lex mercatoria. Columbia Journal of Transnational Law, v. 52, n. 1, p. 372-380, 2013.

50 MUSTILL, Michael J. The new lex mercatoria: the first twentyfive years. Arbitration International: The Journal of LCIA Worldwide Arbitration, v. 4, p. 104-109, 1988. mercatoria como fundamento para dictar determinadas sentencias con efectos en el derecho estatal. También es el caso de GALGANO, quien recoge un pronunciamiento de la Corte Suprema italiana donde esta afirma explícitamente que la lex mercatoria existe porque existe una comunidad empresarial que comparte una serie de valores que se refieren a su actividad (lo cual nos recuerda al adagio latino ubi societas ibi ius); y que existe en dicha comunidad la convicción mayoritaria de que tales valores son vinculantes ${ }^{51}$. Encontramos esta sentencia de un especial interés porque recoge un supuesto donde, a partir de una reflexión teórica sobre qué es derecho, un tribunal estatal reconoce el carácter jurídico de un sistema concreto nacido fuera del ámbito del Estado.

En el momento en que se acepta la existencia de un sistema fundamentalmente no-estatal que regula el comercio internacional, una de las tareas de la doctrina es precisamente la determinación de los elementos que lo componen. Evidentemente, esa es una problemática relacionada con las fuentes del derecho. La versión más reducida de la lex mercatoria, según JEMIELNIAK, sería aquella que considera que son fuentes del derecho de la lex mercatoria las prácticas o usos del derecho mercantil transnacional y los principios generales del derecho. Asimismo, en versiones más amplias, podrían incluirse estándares internacionales para el comercio establecidos por organismos tanto públicos como privados; modelos contractuales o laudos arbitrales ${ }^{52}$. En este ámbito encontramos, de nuevo, propuestas donde los mecanismos tradicionales o de hard law conviven con los de soft law; donde los mecanismos adoptados por los Estados interaccionan con los que surgen de las interacciones comerciales en las que participan las empresas transnacionales. Por ejemplo, CUNIBERTI afirma que la lex mercatoria debe incluir los tratados internacionales sobre cuestiones comerciales que tienen más amplia aceptación; las prácticas y modelos contractuales y los principios generales del derecho ${ }^{53}$.

La cuestión de si las prácticas y modelos contractuales pueden constituir una fuente del derecho (en este caso, del sistema jurídico conocido como lex mercato-

51 Judgment of February 8, 1982, Cass., 1982 Foro It. I, 2285 (It.) 52 JEMIELNIAK, Joanna. Application of transnational substantive rules to commercial disputes: on creative aspects of arbitral decision making. ZIRK-SADOWSKI, Marek; GOLECKI, Mariusz Jerzy; WOJCIECHOWSKI, Bartosz (Ed.). Multicentrism as an emerging paradigm in legal theory. Frankfurt am Main: Peter Lang, 2009. p. 257. 53 CUNIBERTI, Gilles. Three theories of lex mercatoria. Columbia Journal of Transnational Law, v. 52, n. 1, p. 381, 2013. 
ria) es sin duda la más polémica. Al analizarla, TEUBNER afirma que "de acuerdo con la doctrina tradicional de las fuentes del derecho la lex mercatoria, sin duda, es no-jurídica. Puede ser cualquier cosa, normas profesionales, reglas sociales, costumbres, usos, obligaciones contractuales, acuerdos intra- o inter-organizacionales, laudos arbitrales, pero no derecho" ${ }^{54}$. Y añade una afirmación que entendemos muy relevante: la distinción entre lo que es derecho y lo que no lo es se basa en una jerarquía de normas jurídicas donde las normas superiores legitiman a las inferiores, de modo que los fenómenos normativos que quedan fuera de esta jerarquía no son derecho, sino simples hechos. En un sentido similar, GALGANO afirma que "si continuamos concibiendo el contrato como mera aplicación del derecho, y no como una fuente del derecho, resultará imposible entender cómo está cambiando el derecho de nuestros tiempos" $" 55$. Ambos autores coinciden en cuestionar la distinción norma-hecho, o creación-aplicación, en los términos en que se deriva de la concepción jurídica dominante; y ambos están recogiendo aquí una limitación inherente a dicha concepción hegemónica, y sobre la que volveremos luego.

\section{El PROBLEMA DEL PARADIGMA ACTUAL: LIMITACIONES DERIVADAS DEL MONISMO JURÍDICO Y DEL FORMALISMO JURÍDICO}

Tras el análisis de los tres fenómenos anteriores, calificados de soft law por la doctrina mayoritaria, estamos en condiciones de sistematizar una serie de problemáticas que surgieron al intentar incluir este tipo de instrumentos en los modelos que permiten explicar qué es el derecho.

Las resoluciones de la Asamblea General de las Naciones no se consideraban fuentes del derecho internacional en la medida en que se tomaba como parámetro de referencia el artículo 38 del Estatuto del CIJ. Los intentos de la doctrina para ofrecer una explicación de este tipo de instrumentos oscila entre una tendencia más conservadora (emplear las categorías existentes

54 TEUBNER, Gunther. Breaking frames: economic globalisation and the emergence of lex mercatoria. European Journal of Social Theory, n. 5, p. 199-217, 2002.

55 GALGANO, Francesco. The new lex mercatoria. Annual Survey of International \& Comparative Law, v. 2, n. 1, p. 102-103, 1995. para explicar estas resoluciones, asimilándolas a alguno de los elementos que definen la costumbre internacional o vinculándolas con los principios generales del derecho) y otra más innovadora, la creación o aplicación de una nueva categoría, la de soft law.

El uso de esta categoría, que ha acabado por tener un gran éxito y se ha introducido así en la conciencia jurídica a través de la cual se interpreta o se construye la realidad, implica también una evidente expansión del ámbito de los dispositivos que se consideran jurídicos.

En los tres casos analizados, la creación de mecanismos de soft law viene precedido por la emergencia de nuevos actores, que a veces tienen carácter institucional - la Asamblea de la ONU, las instituciones de la Unión Europea- y a veces no, como es el caso de las empresas transnacionales. En el caso de la Asamblea, la modificación en su composición (derivada de los procesos de descolonización) hace que se introduzcan nuevas dinámicas y que se potencie este órgano, el más representativo de la Organización de las Naciones Unidas, para promover una serie de intereses en muy diversos ámbitos.

Según GOLD, por ejemplo, "el ingrediente esencial del soft law es una expectativa de que los Estados que aceptan tales instrumentos tomarán su contenido con seriedad y les concederán cierto grado de respeto" 56 . ¿Tienden los destinatarios de un dispositivo de soft law a cumplirlo? Aunque existen relativamente pocos estudios empíricos sobre el particular ${ }^{57}$, es una cuestión que está recibiendo una atención creciente ${ }^{58}$. A la luz de la escasa información disponible, puede afirmarse que los tratados internacionales y otros acuerdos no vinculantes presentan un grado similar de cumplimiento ${ }^{59}$, dato que entendemos de la mayor relevancia.

56 GOLD, Joseph. Strengthening the soft international law of exchange agreements. The American Journal of International Law, v. 77, p. $443,1983$.

57 SHELTON, Dinah. Commitment and compliance: the role of nonbinding norms in the international legal system. Oxford: Oxford University Press, 2000. p. 11.

58 En el marco del cumplimiento cooperativo fomentado por la OCDE, por ejemplo, se ha planteado de manera expresa la necesidad de poder medir el impacto real de esta experiencia en el cumplimiento de los contribuyentes. OECD. Co-operative compliance: a framework: from enhanced relationship to co-operative compliance. New York: OECD, 2013. Es importante señalar que el cumplimiento cooperativo opera casi exclusivamente a partir de elementos de soft law: no pretende modificar el ordenamiento jurídico, entendido como derecho vinculante.

59 HILLGENBERG, Hartmut. A fresh look at soft law. European Journal of International Law, v. 10, n. 3, p. 502, 1999. 
Pues bien, ¿por qué, si estamos ante elementos que tienen un efecto típicamente jurídico, como es la estabilización de expectativas, o que reflejan la percepción de una colectividad de que determinados valores son vinculantes o deseables, los juristas enfrentan tantas dificultades determinar la naturaleza de estos fenómenos? ¿Cuáles son los problemas que aquejan a los modelos jurídicos más extendidos a la hora de reconocer el carácter jurídico del soft law?

La concepción hegemónica del derecho, de carácter positivista-normativista, conlleva una concepción epistemológica que considera que "conocer" significa describir una realidad puesta. En su aspecto metodológico, el positivismo intenta imitar las ciencias empíricas y asume como científico sólo aquello que puede medirse, pesarse o valorarse matemáticamente. La consecuencia en el ámbito del derecho es "un modelo interpretativo meramente reproductor del Derecho positivo codificado", centrado en la conexión lógica entre los hechos y las hipótesis legislativas ${ }^{60}$. Por su parte, el normativismo considera que el derecho es un conjunto de normas prescriptivas, cuya función es la de influenciar directamente en el comportamiento de su destinatario; normas que a su vez se construyen a través del lenguaje. Probablemente, el mayor exponente del normativismo sea KELSEN, quien definió el derecho como un "orden normativo de coacción" ${ }^{\prime 1}$.

El concepto kelseniano de fuente de derecho es el de "fundamento de validez jurídico-positivo de una norma jurídica"; o, en otras palabras, "la norma jurídica positiva del escalón superior que regula su producción" ${ }^{2}$. La crítica de TEUBNER previamente citada a una "distinción entre lo que es derecho y lo que no lo es" basada "en una jerarquía de normas jurídicas donde las normas superiores legitiman a las inferiores" es una crítica precisamente al modelo kelseniano. Uno de los principales problemas que presenta este modelo es que es un modelo jerárquico y cerrado. Sin embargo, aunque no existe una norma de rango superior que habilite de manera expresa al Consejo a adoptar una resolución como el Código de conducta (que constituye por tanto un acto

60 HOFFMAN, Fernando; CAVALHEIRO, Larissa Nunes; NASCIMENTO, Valéria Ribas do. Do normativismo à principiologia na interpretação/decisão jurídica. Pensar, v. 17, n. 2, jul./dez. p. 454-455, 2012.

61 KELSEN, Hans. Pure theory of law. 2. ed. Berkeley: University of California Press, 1978. p. 48-55.

62 KELSEN, Hans. Pure theory of law. 2. ed. Berkeley: University of California Press, 1978. p. 259. atípico), eso no obsta a su existencia empírica, ni evita que los Estados adecuen la conducta a lo previsto en tal dispositivo, eliminando medidas tributarias que se consideran competencia fiscal lesiva.

Tal vez esta concepción piramidal del derecho -que, además, siempre ha sido conflictiva desde un punto de vista teórico cuando se ha pretendido determinar la regla de cierre- pueda sustituirse por una visión más descentralizada. En este sentido, TEUBNER afirma que la existencia de una regla última de reconocimiento no es sino un mito, que esconde una circularidad del derecho. El derecho sería esencialmente -desde la perspectiva de las teorías autopoiéticas a las que TEUBNER se adscribe- autorreferencial.

Por otra parte, KELSEN afirmó también que no sería jurídica la norma que prescribiera una determinada conducta sin que otra norma estableciese una sanción para el caso de su incumplimiento ${ }^{63}$. Si aceptamos tal asunción, el soft law sería una realidad no-jurídica. La doctrina ha afirmado que la aplicación del soft law se basa, en gran medida, en la buena fe de las partes ${ }^{64}$. Existen además mecanismos de "coacción blanda" o "informales", en virtud de los cuales el cumplimiento no queda estrictamente al arbitrio del destinatario ${ }^{65}$, pero que normalmente no se considera que tengan carácter jurídico.

Además, bajo el paradigma monista imperante, la única coacción admisible es la del Estado (lo cual hace particularmente compleja la admisibilidad, o la comprensión, de la lex mercatoria como sistema jurídico).

El derecho de la Modernidad, caracterizado por su estatalidad, unicidad, positividad y racionalidad, es un producto histórico. Podemos considerarlo una respuesta a las necesidades de la forma de producción capitalista y, fundamentalmente, la unidad de mercado. Fren-

63 KELSEN, Hans. Pure theory of law. 2. ed. Berkeley: University of California Press, 1978. p. 59.

64 ALARCÓN GARCÍA, en un análisis centrado en el sistema jurídico estatal, destaca que estos instrumentos "son dictados acompañados de la buena fe como elemento presente y dominante en las relaciones que establece". ALARCÓN GARCÍA, Gloria. El soft law y nuestro sistema de fuentes. In: PISÓN, Juan Arrieta Martínez de et al (Ed.). Tratado sobre la Ley General Tributaria: Homenaje a Álvaro Rodríguez Bereijo. Cizur Menor: Aranzadi, 2010. p. 293.

65 Los mecanismos de aplicación del Código de conducta son un ejemplo. Otro ejemplo sería el de códigos de buen gobierno corporativo, profusamente empleados en la actualidad: se considera que su incumplimiento tendrá un reflejo negativo en la valoración de la empresa en los mercados financieros. 
te a la fragmentación jurídica propia del feudalismo, la actividad económica de la burguesía exigía un ordenamiento jurídico general y unificado, que vino de la mano del Estado-nación ${ }^{66}$. Este origen explica que el derecho estatal moderno haya tenido tradicionalmente una pretensión de hegemonía, tanto en el ámbito estrictamente normativo como (a través del paradigma del monismo jurídico) en el simbólico.

Como señala SANTOS, al concebirse el Estado como la única forma de poder político-jurídico, la lucha por el poder tiende a reducirse a la lucha por el control de sus instituciones. Todas las luchas sociales se canalizan a través de la estructura estatal, en una serie de procesos y transformaciones que permiten que el derecho del Estado se presente como un instrumento de representación de los intereses de toda la sociedad (a través del sufragio universal) y de respuesta a sus necesidades (garantiza tanto la unidad de mercado como el Estado del bienestar ${ }^{67}$. Los fenómenos descritos produjeron una "despluralización” jurídica y permitieron que el Estado sostuviera con cierto éxito un paradigma monista que ocultaba la pervivencia, pese a todo, de muchos otros relatos de construcción normativa de la realidad.

La situación ha cambiado paulatinamente y creemos que no es excesivamente polémico afirmar que no puede hablarse de esferas excluyentes de soberanía en el mundo actual. Esto es evidente en la Unión Europea, donde el concepto de soberanía se ha convertido en algo fuertemente limitado, en la medida en que muchas de las competencias que permiten reconocer a un Estado como tal han pasado a ser competencias exclusivas de la Unión Europea (como la emisión de moneda) o competencias compartidas entre la Unión y los Estados miembros. Pero, en general, fenómenos como la transformación de los derechos humanos tras la segunda guerra mundial o los diversos procesos de globalización, entre ellos -pero no solo- la globalización económica, son elementos de erosión de la soberanía. Para entender el momento actual es más necesario que nunca abandonar el monismo jurídico para establecer un paradigma pluricéntrico, o tal vez sin un centro preciso.

66 WOLKMER, Antonio Carlos. Pluralismo jurídico: fundamentos de uma nova cultura no direito. São Paulo: Alfa-Ômega, 2001. p. 40. 67 SANTOS, Boaventura de Sousa. Crítica de la razón indolente: contra el desperdicio de la experiencia. Para un nuevo sentido común: la ciencia, el derecho y la política en la transición paradigmática. Bilbao: Desclée, 2003. v. 1. p. 165-168.

\section{LA NECESIDAD DE UNA VISIÓN MÁS AMPLIA DEL DERECHO: ¿QUÉ NOS OFRECE LA TEORÍA DE LOS SISTEMAS DINÁMICOS COMPLEJOS?}

El soft law es un fenómeno de evidente heterogeneidad. Su definición y su interacción con el hard law presentan aspectos de difícil sistematización. Para ofrecer una nueva configuración, puede ser necesario dar un paso atrás y repensar nuestra concepción del sistema jurídico. Los juristas no siempre disponemos de un marco epistemológico claro y suficientemente elaborado para afrontar todos los problemas que ofrece el análisis del derecho. Estas son algunas de las cuestiones problemáticas que hemos detectado a lo largo del trabajo: ¿cómo tratar la inclusión de nuevos actores en un sistema jurídico? ¿Qué naturaleza o rango jurídico debemos atribuir a los mecanismos a través de los que se expresan y que, muchas veces, no están previstos en la norma constitucional -entendida en sentido lato- del ordenamiento correspondiente? ¿Cómo interaccionan con los elementos "oficiales" del sistema?

El objetivo de este epígrafe es esclarecer tales cuestiones, tomando como referencia teórica la teoría de los sistemas dinámicos complejos, tal y como ha sido aplicada al ámbito jurídico por el profesor estadounidense J. B. RUHL. Este autor ha sugerido que el sistema jurídico puede estudiarse a la luz de los estudios sobre sistemas en otras ciencias y analizarse a partir de los agentes que operan en ellos, de cómo interactúan y de cuál es el resultado emergente de dicha interacción. Vamos a desarrollar esta idea.

Empezamos por afirmar que el derecho no es un sistema cerrado, sino abierto. Su carácter abierto se refiere a la continua interacción con su entorno ${ }^{68}$. Como señala RODRÍGUEZ-M., es necesario "rechazar la idea más difundida de que el derecho es un sistema de normas que se transforma y evoluciona internamente, es decir, a través de los mecanismos inherentes a su propio sistema normativo de funcionamiento" ${ }^{9}$. El derecho, en tanto que sistema, genera un continuo intercambio de información con su medio.

El derecho es un sistema dinámico, y por tanto en continuo cambio. Esto es consecuencia de una serie de

68 LUHMANN, Niklas. Die Wissenchaft der Gesellchaft. Frankfurt am Main: Suhrkamp, 1990. p. 30.

69 RODRÍGUEZ-M., Eduardo. Pluralismo jurídico: ¿el derecho del capitalismo actual? Nueva sociedad, n. 112, p. 93, mar/abr. 1991. 
elementos que podemos encontrar en cualquier sistema jurídico, incluido el internacional: la heterogeneidad de agentes (en el caso del derecho internacional, Estados y organizaciones internacionales; así como diversos grupos -movimientos de liberación nacional, grupos beligerantes- o la propia persona física, bajo determinadas circunstancias y límites), las existencia de relaciones no-lineares y de un alto grado de retroalimentación entre los agentes, lo cual crea una red de nodos y canales a través del cual se transmite la información ${ }^{70}$.

Esto genera diversas cuestiones que deben tenerse en cuenta para cualquier análisis. La primera es que es conveniente un enfoque más centrado en los agentes y en la interacción entre ellos, como elementos básicos del sistema $^{71}$. Parte de la doctrina ha señalado que la fuente primaria del derecho se encontraría en lo que WOLKMER denomina la "dinámica interactiva" de la sociedad humana ${ }^{72}$. Según TEUBNER, sus elementos básicos "son comunicaciones, no normas: el derecho no es un sistema de normas, tal y como pretenden las teorías analítico-normativistas" "73. De ese modo, la aparición de nuevos dispositivos jurídicos en un sistema (como el soft law) no debe analizarse desde la perspectiva de las normas (hemos señalado los problemas que causa dicho modelo), sino que es necesario analizar la aparición de nuevos agentes en el sistema y su interacción con los que ya existían. La teoría de los sistemas adaptativos complejos nos explica, según CASTI y GOLDSTEIN, que la aparición de un nuevo agente en un determinado medio provoca cambios imprevisibles en el sistema ${ }^{74}$.

Desde una perspectiva basada en último término en la interacción entre agentes, como la que nos ofrece el modelo de los sistemas adaptativos complejos, podemos explicar por qué el grado en que un instrumento de soft law es vinculante no depende exclusiva y necesariamente de la voluntad de las partes, sino de la "in-

70 RUHL, John B. Law's complexity: a primer. Georgia State University Law Review, v. 24, n. 4, p. 895, 2008.

71 FOLLONI, André. Introdução à teoria da complexidade. Curitiba: Juruá, 2016. p. 64.

72 WOLKMER, Antonio Carlos. Pluralismo jurídico: fundamentos de uma nova cultura no direito. São Paulo: Alfa-Ômega, 2001. p. 138.

73 TEUBNER, Gunther. El derecho como sujeto epistémico: hacia una epistemología constructivista del derecho. Doxa: Cuadernos de Filosofía del Derecho, n. 25, p. 533, 2002.

74 CASTI, John L. Complexification: explaining a paradoxical world through the science of surprise. New York: Harper Perennial, 1995. p. 9; GOLDSTEIN, Jeffrey. Emergence as a construct: history and issues. Emergence, v. 1, n. 1, p. 60, 1999. terdependencia factual" creada por sus acciones y por la interacción con una serie de elementos estructurales del sistema ${ }^{75}$. Como afirman las teorías constructivistas, "los actores sociales no existen independientemente de su entorno social y sus sistemas de significados compartidos colectivamente" ${ }^{\text {" }}$. En un sistema adaptativo complejo no existe necesariamente un agente central del sistema jurídico, sino una arquitectura auto-organizada en forma de red, consecuencia de las interacciones producidas a lo largo del tiempo bajo un criterio de dependencia del camino ("path-dependence") ${ }^{77}$.

En resumen, desde la perspectiva de la teoría de los sistemas adaptativos complejos propuesta, el ordenamiento jurídico sería el producto emergente del sistema jurídico, entendido este a su vez como un conjunto de personas e instituciones que interaccionan entre $\mathrm{si}^{78}$.

Una ampliación del concepto de derecho nos obliga, al mismo tiempo, a determinar cuál es su límite. Nuestra concepción de derecho tiene como elemento básico las interacciones entre una serie de agentes, pero estas interacciones - en la forma de actos comunicativos- pueden desplegar efectos en otros sistemas, como el moral, el político o el económico. En este sentido, consideramos que lo que caracteriza al sistema jurídico es que es un mecanismo de estabilización de expectativas; pero, en último término, lo que determina que una norma sea jurídica es que los propios agentes del sistema la consideren como tal. Si un juez decidiera explícitamente sobre la base de argumentos morales, el sistema jurídico podría reaccionar contra la sentencia pronunciada. Esto es así porque se consideraría un elemento extraño al sistema.

La aceptación de una norma como jurídica es una cuestión que sólo puede determinarse mediante la observación. HART denomina "reglas de reconocimiento" a aquellas cuya función es proporcionar criterios

75 Véase HILLGENBERG, Hartmut. A fresh look at soft law. European Journal of International Law, v. 10, n. 3, p. 499-515, 1999. p. 505 , aunque este autor considera que lo fundamental es la voluntad de las partes.

76 TRUBEK, David M.; COTTRELL, Patrick; NANCE, Mark. 'Soft law', 'hard law' and EU integration: toward a theory of hybridity. University of Wisconsin Legal Studies Research Paper, n. 1002, p. 72, nov. 2005. La traducción es propia.

77 HOLLAND, John. Complex adaptive systems. Deadalus, v. 121, n. 1, p. 20, 1992; RUHL, John B. Law's complexity: a primer. Georgia State University Law Review, v. 24, n. 4, p. 895, 2008.

78 RUHL, John B. Law's complexity: a primer. Georgia State University Law Review, v. 24, n. 4, p. 897, 2008. 
de autoridad que permitan determinar qué normas son jurídicamente válidas y cuáles no lo son; muchas veces estas reglas de reconocimiento no se enuncian de manera expresa, pero su existencia se muestra de manera implícita en la actuación de jueces u otros aplicadores del derecho ${ }^{79}$. En el ámbito del soft law, existen varios estudios muy interesantes que analizan la recepción de este tipo de normas en la jurisprudencia. Varios ejemplos, ampliamente citados a lo largo de este trabajo, son el análisis de KERWIN sobre la invocación de las resoluciones de la Asamblea General de la ONU en los tribunales estadounidenses o los diferentes análisis sobre la aplicación de la lex mercatoria por los jueces estatales.

La diferencia con el modelo de HART es que el carácter dinámico del sistema, unido a su carácter descentralizado, implica que no existe en ningún momento una "última palabra" sobre una cuestión, sino que los diferentes agentes expresan sus pareceres sobre la base de una determinada estructura. La teoría que estamos aplicando nos proporciona una serie de herramientas metodológicas para analizar la interacción entre el soft law y el hard law, que es una cuestión que la doctrina ha analizado profusamente ${ }^{80}$ : el soft law expresaría, como mínimo, una convergencia de voluntades que puede dar lugar a una cooperación mutua que se desarrolle en un determinado sistema.

El soft law, como decíamos en la introducción, es manifestación del desbordamiento del sistema de fuentes. Esta idea puede explicarse a la luz de la diferenciación tradicional entre fuentes materiales y formales del derecho ${ }^{81}$. Las fuentes materiales serían aquellos factores, fenómenos o acontecimientos de naturaleza sociológica que contribuyen a construir el discurso jurídico. Las fuentes formales se refieren a los órganos legitimados para crear derecho y a los procedimientos mediante los que se crea. Establecen, por tanto, unas reglas de producción que determinan que la norma sea

79 HART, Herbert. L. A. El concepto de derecho. Buenos Aires: Abeledo-Perrot, 2004. p. 117-118.

80 Por ejemplo, DUPUY, describe el papel de las resoluciones de la Asamblea General de las Naciones Unidas en la reformulación de la costumbre con motivo de la ascensión del llamado "grupo de los 77", formado por antiguas colonias: DUPUY, Rene-Jean. Droit déclaratoire et droit programmatoire: de la coutume sauvage à la 'soft law'. In: Société Française pour le Droit International (Ed.). L'Élaboration du droit international. Paris: Pedone, 1975. p. 137139.

81 MONTORO BALLESTEROS, Manuel Alberto. Ideologías y fuentes del derecho. Anales de Derecho, v. 6, p. 58-62, 1984. válida $^{82}$. Ahora bien, las fuentes formales se establecen desde el interior de un determinado ordenamiento jurídico y desde determinada perspectiva. Pueden considerarse la cristalización del sistema de fuentes materiales en un momento determinado: un ejemplo, que hemos mencionado previamente, es la redacción del artículo 38 del Estatuto de la CIJ.

Los cambios sociales, económicos y políticos de la segunda mitad del siglo XX han dejado atrás los marcos tradicionales de creación de normas. El sistema de fuentes (formales) estatal está en crisis porque el discurso que genera no es suficiente para explicar la realidad jurídica cotidiana. El fortalecimiento de nuevas subjetividades (tanto en el ámbito internacional como en el ámbito interno) produce nuevos actores con capacidad para la creación de reglas. En otras palabras, el sistema de fuentes formales ha sido desbordado por el sistema de fuentes materiales. Uno de los motivos para adoptar dispositivos de soft law es la de poder incluir a sujetos que no pueden suscribir tratados internacionales de acuerdo con las reglas de derecho internacional, a partes cuya competencia o jurisdicción es limitada o a sujetos que alguna de las partes no reconoce como sujetos de derecho internacional.

Hemos afirmado que, frente a la concepción kelseniana de sistema cerrado y jerárquico, aplicamos un modelo que describe un sistema abierto y sin centro. La formulación expresa del sistema de fuentes materiales es, de hecho, un acto comunicativo más, formulado por un agente específico, y que será acogido en mayor o menor grado por el resto de agentes. Eso explica por qué un juez puede, en cualquier momento, decidir una cuestión sobre la base de una fuente del derecho no prevista en el artículo 38 del Estatuto de la CIJ o en cualquier otra norma con pretensión "constitucional".

Consideramos relevante hacer aquí una puntualización. Nuestro análisis está centrado en el Derecho internacional, que constituye un sistema jurídico particularmente abierto. Dentro de los sistemas complejos podemos encontrar configuraciones muy diferentes que determinen respuestas ante una misma perturbación. El diseño del sistema puede tender a la recuperación del estado de equilibrio en el menor tiempo posible o, por el contrario, a la introducción de ajustes a los procesos del sistema para recomponer la integridad global del sis-

82 MONTORO BALLESTEROS, Manuel Alberto. Ideologías y fuentes del derecho. Anales de Derecho, v. 6, p. 59, 1984. 
tema ${ }^{83}$. Este segundo modelo es más flexible (y recuerda más a la estructura del sistema de fuentes en el Derecho internacional), mientras que el primer modelo es más rígido (similar al sistema de fuentes en la Constitución de un Estado, por ejemplo). Ninguno de los dos modelos va a encontrarse en estado puro y, en ambos casos, la existencia de reglas definidas puede verse desbordada; pero deben trasladarse con cautela estas afirmaciones al ámbito del Derecho interno.

\section{Conclusiones}

El concepto de fuentes del derecho, a la luz de la teoría de los sistemas dinámicos complejos, se convierte en una cuestión abierta. A nuestro entender, la categoría del soft law es uno de los mejores ejemplos de ello. Constituye un concepto omnicomprensivo de creación doctrinal que, históricamente, ha tratado de acoger o reflejar esta realidad evolutiva en muy diversos contextos.

Cada dispositivo normativo - como el tratado, la costumbre, la declaración o el modelo contractual- es el producto emergente de la interacción entre los agentes que componen el sistema. Esto implica que la introducción de nuevos agentes o de nuevos modos de interacción entre ellos puede y suele resultar en la emergencia de nuevos dispositivos normativos. La extensión del concepto de soft law, inicialmente en la doctrina y posteriormente en las instituciones, resulta ser un ejemplo de ello, a la luz de lo descrito en este trabajo.

El sistema de fuentes es un producto emergente de la interacción entre sujetos y puede ser más o menos rígido en función de cómo se produzca dicha interacción. Una de las consecuencias de tal naturaleza emergente es la dificultad de establecer un elenco que contenga todas las fuentes de un determinado sistema jurídico. Además, aunque se consiguiera tal completitud, la dinamicidad del sistema hace que toda lista que se pretenda cerrada sea, como mínimo, provisional. Partiendo de la idea de que cada sistema jurídico es una red sin un centro claro -algo más evidente aún en el derecho internacional-, todo intento de limitar las fuentes de producción de derecho no es sino un acto comunicativo emitido por

83 RUHL, John B. General design principles for resilience and adaptive capacity in legal systems - With applications to climate change adaptation. North Carolina Law Review, v. 89, p. 1376-1377, 2011. alguno de los agentes del sistema, que otros agentes no tienen por qué - dentro de cierto margen- tener necesariamente en cuenta.

\section{Referencias}

ADAMCZYK, Łukasz; MAJDAŃSKA, Alicja, The sources of EC law relevant for direct taxation. In: LANG, Michael et al. Introduction to european tax law: direct taxation. Vienna: Spiramus Press, 2008.

ALARCÓN GARCÍA, Gloria. El soft law y nuestro sistema de fuentes. In: PISÓN, Juan Arrieta Martínez de et al (Ed.). Tratado sobre la Ley General Tributaria: Homenaje a Álvaro Rodríguez Bereijo. Cizur Menor: Aranzadi, 2010. p. 271-298.

ALONSO GARCÍA, Ricardo. El soft law comunitario. Revista de Administración Pública, n. 154, 2001.

BLEICHER, Samuel A. The legal significance of recitation of General Assembly Resolutions. The American Journal of International Law, v. 63, n. 3, jul. 1969.

CASTAÑEDA, Jorge. Legal Effects of United Nation Resolutions. New York: Columbia University Press, 1969.

CASTI, John L. Complexification: explaining a paradoxical world through the science of surprise. New York: Harper Perennial, 1995.

CHRISTOL, Carl Q. Communist China and international law: strategy and tactics. The Western Political Quarterly, v. 21, n. 3, Sep. 1968.

CRAIG, Paul; DE BÚRCA, Gráinne. EU Law: text, cases, and materials. 6. ed. Oxford: Oxford University Press, 2015.

CUNIBERTI, Gilles. Three theories of lex mercatoria. Columbia Journal of Transnational Law, v. 52, n. 1, 2013.

D'ASPREMONT, Jean. Softness in international law: a self-serving quest for new legal materials. The European Journal of International Law, v. 19, n. 5, 2008.

DEL TORO HUERTA, Mauricio Iván. El fenómeno del soft law y las nuevas perspectivas del Derecho internacional. Anuario Mexicano de Derecho Internacional, v. 6, 2006.

DUPUY, Rene-Jean. Droit déclaratoire et droit programmatoire: de la coutume sauvage à la 'soft law'. In: Société Française pour le Droit International 
(Ed.). L'Élaboration du droit international. Paris: Pedone, 1975. p. 132-148.

FALK, Richard A. On the quasi-legislative competence of the General Assembly. The American Journal of International Law, v. 60, n. 4, Oct. 1966.

FOLLONI, André. Introdução à teoria da complexidade. Curitiba: Juruá, 2016.

FOOTER, Mary E. The (re)turn to 'soft law' in reconciling the antinomies in WTO law. Melbourne Journal of International Law, v. 11, 2010.

FRANCK, Thomas. The power of legitimacy among nations. Oxford: Oxford University Press, 1990.

GALGANO, Francesco. The new lex mercatoria. Annual Survey of International \& Comparative Law, v. 2, n. 1, 1995.

GOLD, Joseph. Strengthening the soft international law of exchange agreements. The American Journal of International Law, v. 77, 1983.

GOLDSTEIN, Jeffrey. Emergence as a construct: history and issues. Emergence, v. 1, n. 1, p. 60, 1999.

GRIBNAU, Hans. Soft law and taxation: EU and international aspects. Legisprudence, v. 2, n. 2, 2008.

GROSS, Leo. The United Nations and the role of law. International Organization, v. 19, n. 3, 1965.

HART, Herbert. L. A. El concepto de derecho. Buenos Aires: Abeledo-Perrot, 2004.

HASSAN, Parvez. The international covenants on human rights: an approach to interpretation. Buffalo Law Review, v. 19, n. 3, p. 35-50, 1970.

HIGGINS, Rosalyn. The development of international law by the political organs of the United Nations. Proceedings of the American Society of International Law at Its Annual Meeting, v. 59, p. 116-124, Apr. 1965.

HILLGENBERG, Hartmut. A fresh look at soft law. European Journal of International Law, v. 10, n. 3, p. 499515, 1999.

HOFFMAN, Fernando; CAVALHEIRO, Larissa Nunes; NASCIMENTO, Valéria Ribas do. Do normativismo à principiologia na interpretação/decisão jurídica. Pensar, v. 17, n. 2, jul./dez. 2012.

HOLLAND, John. Complex adaptive systems. Deadalus, v. 121, n. 1, p. 20, 1992.
HOOF, Godefridus van. Rethinking the sources of international law. Deventer: Kluwer, 1983.

JEMIELNIAK, Joanna. Application of transnational substantive rules to commercial disputes: on creative aspects of arbitral decision making. ZIRKSADOWSKI, Marek; GOLECKI, Mariusz Jerzy; WOJCIECHOWSKI, Bartosz (Ed.). Multicentrism as an emerging paradigm in legal theory. Frankfurt am Main: Peter Lang, 2009. p. 247-270.

KELSEN, Hans. Pure theory of law. 2. ed. Berkeley: University of California Press, 1978.

KERCHOVE, Michel van de; OST, François. Le droit et les paradoxes du jeu. Paris: PUF, 1992.

KERWIN, Gregory J. The role of United Nations General Assembly resolutions in determining the principles of international law in United States courts. Duke Law Journal, n. 4, 1983.

LUHMANN, Niklas. Die Wissenchaft der Gesellchaft. Frankfurt am Main: Suhrkamp, 1990.

MENKE, Christoph; POLLMANN, Arnd. Filosofía de los derechos humanos. Barcelona: Herder, 2010.

MONTORO BALLESTEROS, Manuel Alberto. Ideologías y fuentes del derecho. Anales de Derecho, v. 6, p. 55-84, 1984.

MUSTILL, Michael J. The new lex mercatoria: the first twenty-five years. Arbitration International: The Journal of LCIA Worldwide Arbitration, v. 4, p. 86-119, 1988.

OECD. Co-operative compliance: a framework: from enhanced relationship to co-operative compliance. New York: OECD, 2013.

PETERSON, M. J. The UN General Assembly. Abingdon: Routledge, 2006.

PROST, Mario. The concept of unity in public international law. Oxford: Hart Publishing, 2012.

ROBILANT, Anna di. Genealogies of Soft Law. The American Journal of Comparative Law, v. 54, n. 3, p. 499554, 2006.

ROCCATAGLIATA, Franco. Diritto tributario comunitario. In: UCKMAR, Victor (ed.). Diritto tributario internazionale. Padova: CEDAM, 2005.

RODRÍGUEZ-M. Eduardo. Pluralismo jurídico: ¿el derecho del capitalismo actual? Nueva sociedad, n. 112, p. 91-101, mar./abr. 1991. 
RUHL, John B. General design principles for resilience and adaptive capacity in legal systems - With applications to climate change adaptation. North Carolina Law Review, v. 89, p. 1373-1401, 2011.

RUHL, John B. Law's complexity: a primer. Georgia State University Law Review, v. 24, n. 4, 2008.

SANTOS, Boaventura de Sousa. Crítica de la razón indolente: contra el desperdicio de la experiencia. Para un nuevo sentido común: la ciencia, el derecho y la política en la transición paradigmática. Bilbao: Desclée, 2003. v. 1.

SCHACHTER, Oscar. The quasi-judicial role of the Security Council and the General Assembly. The American Journal of International Law, v. 58, n. 4, p. 960-965, Oct. 1964.

SENDEN, Linda. Soft law in European Community law. Oxford: Hart Publishing, 2004.

SHELTON, Dinah. Commitment and compliance: the role of non-binding norms in the international legal system. Oxford: Oxford University Press, 2000.

SWEET, Alec Stone. The new lex mercatoria and transnational governance. Journal of European Public Policy, n. 13, p. 627-646, 2006.
TEUBNER, Gunther. Breaking frames: economic globalisation and the emergence of lex mercatoria. European Journal of Social Theory, n. 5, p. 199-217, 2002.

TEUBNER, Gunther. El derecho como sujeto epistémico: hacia una epistemología constructivista del derecho. Doxa: Cuadernos de Filosofía del Derecho, n. 25, p. 533-571, 2002.

THÜRER, Daniel. The role of soft law in the actual process of european integration. In: Jacot-Guillarmod, O.; Pescatore, P. (Ed.), L'avenir du libre-échange en Europe: vers un espace économique européen? Zürich: Schultess Polygraphischer Verlag, 1990.

TRUBEK, David M.; COTTRELL, Patrick; NANCE, Mark. 'Soft law', 'hard law' and EU integration: toward a theory of hybridity. University of Wisconsin Legal Studies Research Paper, n. 1002, nov. 2005.

VALNDERBILT, Arthur T. The law school in a changing society: a law center. American Bar Association Journal, n. 32, 1946.

WOLKMER, Antonio Carlos. Pluralismo jurídico: fundamentos de uma nova cultura no direito. São Paulo: AlfaÔmega, 2001. 
Para publicar na Revista de Direito Internacional, acesse o endereço eletrônico www.rdi.uniceub.br ou www.brazilianjournal.org.

Observe as normas de publicação, para facilitar e agilizar o trabalho de edição. 